\title{
How can the company choose the best web designer? Decision-making application within a company
}

\author{
Blanka Bazsova* \\ Faculty of Economics, VSB - Technical University of Ostrava, Ostrava, Czech Republic
}

\section{A RT ICLE INFO}

\section{Article history:}

Received 27 August 2018

Received in revised form

9 December 2018

Accepted 12 December 2018

\section{Keywords:}

Criteria

Decision-making

Problem solving

Web designer

\begin{abstract}
A B S T R A C T
The demand for web designers is currently increasing, and HR managers are looking for the most suitable candidates for this position. Consequently, HR departments need to thoroughly assess such job seekers in the admission process. The purpose of this paper is to help HR managers to identify criteria for best web designers and evaluate their relevance for the admission process. The admission process is based on a questionnaire, interview and tests. Generally, the role of HR manager is to summarize information from the Curriculum Vitae. The aim of this paper is to choose the criteria for the web designer position in the admission process and evaluate them according to the utility and risk. As a result, the best applicant for the position is chosen on the basis of a decision-making process which follows several assessment criteria. This process ensures an objective assessment of the main criteria among a number of choices. HR managers do not use these objective and quantitative methods, which evaluate the choices according to a set of criteria. Such an evaluation will shorten the time required to judge the appropriate candidate. Then the subsequent interview may be focused only on assessing the candidate's social and managerial competencies. The most appropriate applicant is chosen according to the evaluation of seven main criteria defined in this article.
\end{abstract}

(C) 2019 The Authors. Published by IASE. This is an open access article under the CC BY-NC-ND license (http://creativecommons.org/licenses/by-nc-nd/4.0/).

company from its competitors. According to Purcarea et al. (2017) the emphasis will be on quality, relevance, and design of the posts, the added value they bring to the work and company's productivity. The process begins with the following steps: The basis of the web designer's work is to know the needs and goals of the organization, its products and services to choicely analyze the current status and behavior of visitors on an existing e-shop site and then follows a draft information and functional structure. A so-called wireframe is created. It is a wireframe representing the structure of the design, the layout of individual elements and the overall concept of operation.

That is why the role of the web designer is very important. The results of his work will influence how customers will perceive this online strategy and how they will accept it. Web designer identifies and prepares graphic design, layout of information on the page and basic structure of web pages on the Internet. Using graphical hardware and software, it creates a graphical look of web pages. Together with the project, he leads the project documentation, prepares and implements designs, reproductions, and website layouts. He creates graphical symbols and libraries of such graphic elements for further use. He cooperates with other experts in the team to 
finalize the website. So the position of web designer in the company is so important and the IT management should assess web designer seeker in the admission process thoroughly. In these cases, HR managers can help with the objectivizing decisionmaking process by quantifying the main criteria for his acceptance. The aim of this paper is to choose and assess the criteria in an admission process for the web designer position with including potential risks.

\section{Decision-making process}

Speaking theoretically, we conceptualize the decision making as a process of selection between minimal two possibilities or choices. Charlesworth (2017) stated that the decision analysis is timetested set of tools which can help to develop and examine choices, analyze risks and uncertainty systematically and achieve the goals. As a result of it we get a selection of the best version, which best complies with the specified criteria (aspects of the target of the decision making). The decision-making has multi-criterial dimension; it means that we make decision not on the basis of one criterion, but on the basis of several criteria. Pineda et al. (2018) stated that there large number of complex factors which will be involved and created the multi-criteria decision making (MCDM) to the problem. Factors should be evaluated by experts. The decision-making has similar and characteristic features, for example the decision-making stages, procedures and methods. It is a matter of the formal-logical aspect.

The decision-making is one of the most important activities executed by managers. They use decision making to solve complex problem with many criteria. That is why we speak about the multicriteria decision making where there are a large number of tools and solutions available. Anderson et al. (1988) emphasized that the problem is complex, and the manager cannot develop a good solution without the help of quantitative specialists.

Decision-making is the process of few crucial steps. Some of the problems cannot be solved without the qualitative analysis based upon managerial experience and quantitative analysis based upon mathematical tools. Therefore it is necessary that the subject of the decision-making uses a creative attitude, extensive knowledge and experience, as well as formalized methods and procedures, i.e. heuristics. These problems can't be solved by means of a single-shot decision-making.

Many authors used the decision-making in material engineering and manufacturing process (Zaman et al, 2018). It is usually used not only in the company management, but also in the strategic management, the organizational design and the personnel sphere. Khan (2018) implemented it together with SWOT analysis by prioritizing the strategy in Iranian gas industry. Castro-Nuño and
Arévalo-Quijada (2018) applied the decision-making to minimize traffic accidents.

The quality of the manager's decision influences the effectiveness of separate activities and operation of the enterprise itself, the company's position, as well as prestige and recognition of the manager within this enterprise. If the manager is experienced and has the leadership skills, it contributes to the better performance of the department and whole organization ( ̌̌eháček, 2015).

Multi-criteria decision-making is one of universal heuristic methods applicable in every part of managers' activities. Ministr (2013) claimed that human resources and their optimal utilization contribute to achievement of the aims of IT department and also of the entire company (Ministr, 2013). Phases of decision-making process are displayed in Fig. 1.

\subsection{Managerial problem, its definition and goal setting}

Decision-making process starts with the identification and recognition of the problem. The problem should be described clearly. It is necessary to specify the goal that we want to achieve.

\subsection{Determination of criteria}

After closing of previous step, it is necessary to create the list of criteria. Criteria are the point of view that we judge choices. We distinguish between revenue and cost criteria. The criteria should be compared and we should estimate the criteria importance. There are a large number of methods available for mutual comparison of criteria, such as Fuller's triangle, Saatys' matrix, etc. Saaty's matrix will be applied in this case study that is why it will be described in more details.

\subsection{Evaluation of criteria by Saaty's matrix}

Saaty's method supports the evaluation of preferences among criteria and it has been used in this case study. Table 1 shows the comparison of criteria using Saaty's matrix.

$\left(\begin{array}{ccc}s_{11} & s_{12} & s_{1 n} \\ 1 / s_{12} & 1 & s_{2 n} \\ 1 / s_{1 n} & 1 / s_{12} & 1\end{array}\right)$

Saaty's matrix is the quadrat matrix, $S=\left\{\mathrm{S}_{\mathrm{ij}}\right\}$, where $i, j=1,2, \ldots, n$.

Table 1: An example of a table

\begin{tabular}{cc}
\hline Value & Criteria Evaluation \\
\hline 1 & equal importance among elements $\mathrm{i}$ and $\mathrm{j}$ \\
3 & moderate importance of $\mathrm{i}$ element before $\mathrm{j}$ element \\
5 & strong importance of $\mathrm{i}$ element before $\mathrm{j}$ element \\
7 & very strong importance of $\mathrm{i}$ element before $\mathrm{j}$ element \\
9 & the extreme importance element $\mathrm{i}$ before $\mathrm{j}$ \\
\hline
\end{tabular}




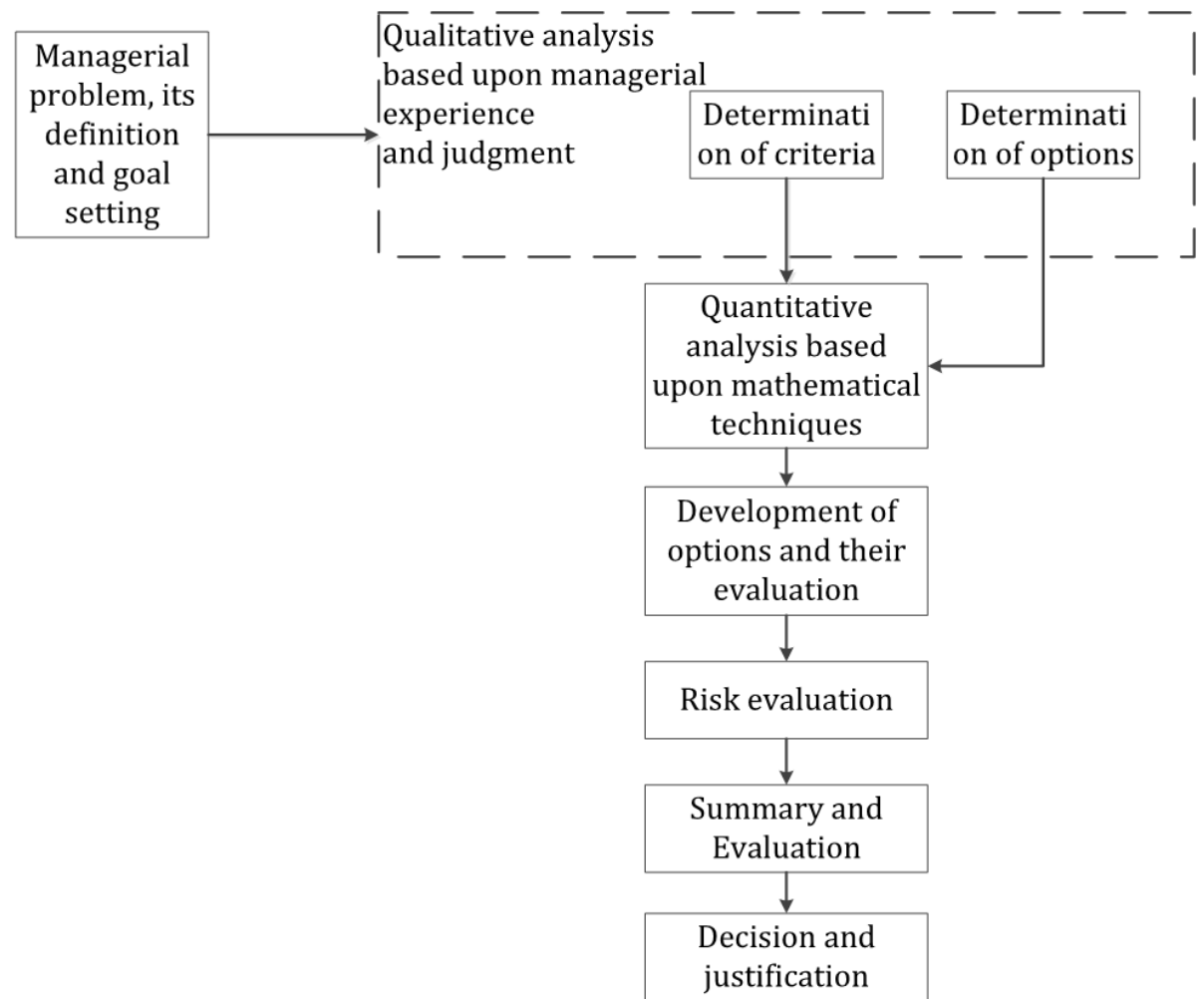

Fig. 1: Framework of decision-making process. Source: adapted according to the Anderson et al. (1988)

Saaty and Vargas (2001) used the 9-escalate scale of the criteria evaluation (Table 1). We compare criteria mutually and determine the preferences. The element of the matrix $s_{i j}$ expresses the weights of $\mathrm{i}$-th and $\mathrm{j}$-th criterion. The weight expresses how much is the the $\mathrm{i}$ - criteria preferred than the $\mathrm{j}$-criteria. On the diagonal, there are displayed notes 1.

$\mathrm{s}_{\mathrm{ij}} \approx \frac{\mathrm{w}_{\mathrm{i}}}{\mathrm{w}_{\mathrm{j}}}$

where $w_{i}$ is weight of $\mathrm{i}$-th criterion and $\mathrm{w}_{\mathrm{j}}$ is weight of j-th criterion.

\subsection{Development of options and their evaluation through the utility calculation}

Options should be described and evaluated. We can use to summarize the information into simple table. The framework for processing of the decisionmaking by using Saaty's matrix and matrixes of utilities has been implemented. For the evaluation of the options, 3 matrixes are used - matrix of absolute utilities, matrix of simple utilities and matrix of weighted utilities.

Matrix of absolute utilities enables to define criteria, express them in original units and express evaluating of each option based on each criterion (Table 2).

Table 2: Description of quantitative and qualitative criteria and options

\begin{tabular}{ccccc}
\hline \multirow{2}{*}{ Criteria } & $\begin{array}{c}\text { Criteria } \\
\text { expression }\end{array}$ & $\mathrm{O}_{1}$ & $\mathrm{O}_{2}$ & $\mathrm{O}_{\mathrm{n}}$ \\
\hline $\mathrm{C}_{1}$ & verbal (scale) & excellent & bad & good \\
$\mathrm{C}_{2}$ & numerically & $100 €$ & $120 €$ & $130 €$ \\
$\ldots$ & value & truth/ & untruth/ & truth/ \\
$\ldots$ & & yes & no & yes \\
\hline
\end{tabular}

Matrix of simple utilities transforms the matrix of absolute utilities. All options are converted into the same uniform variable in the matrix of simple utilities. The best option is evaluated as $100 \%$. Other options have lower evaluation (Table 3).

Table 3: Weighted criteria

\begin{tabular}{|c|c|c|c|c|c|}
\hline \multicolumn{2}{|c|}{$\mathrm{C}_{\mathrm{m}}$} & verbal (scale) & excellent & very good & good \\
\hline $\mathrm{C}$ & $\mathrm{W}$ & $\mathrm{WO}_{1}$ & $\mathrm{WO}_{2}$ & $\mathrm{WO}_{\mathrm{n}}$ & $\mathrm{WO}_{\max }$ \\
\hline $\mathrm{C}_{1}$ & 5 & 500 & 50 & 300 & 500 \\
\hline $\mathrm{C}_{2}$ & 1 & 50 & 60 & 100 & 100 \\
\hline $\mathrm{C}_{\mathrm{m}}$ & 2 & 80 & 200 & 20 & 200 \\
\hline TU & & $\sum \mathrm{WO}_{1}$ & $\sum \mathrm{WO}_{2}$ & $\sum \mathrm{WO}_{\mathrm{n}}$ & $\sum \mathrm{WO}_{\max }$ \\
\hline RUI & & $\sum \mathrm{WO}_{1}$ & $\sum \mathrm{WO}_{2}$ & $\sum \mathrm{WO}_{\mathrm{n}}$ & \\
\hline KU & & $\overline{\sum \mathrm{WO}_{\max }}$ & $\overline{\sum \mathrm{WO}_{\max }}$ & $\overline{\sum \mathrm{WO}_{\max }}$ & \\
\hline
\end{tabular}

There are shown evaluated options with the weight in matrix of weighted utilities in the Table 4, where the utility is expressed as

$\mathrm{U}_{\mathrm{i}}=\mathrm{u}_{\mathrm{i}} \times \mathrm{w}_{\mathrm{j}}$

The relative utility is expressed as

$\mathrm{RU}_{\mathrm{i}}=\frac{\sum_{\mathrm{i}=1}^{\mathrm{n}} \mathrm{Wo}_{\mathrm{i}}}{\mathrm{WO}_{\max }}$.

\subsection{Risk evaluation}

After the evaluation of the options it is necessary to evaluate the risk. Business risks are high risks and enterprise decisions and funding for the development and deployment of new products are the biggest business risks. Risk can be managed, minimized, shared, transferred or accepted but it cannot be ignored (Řeháček, 2018). 
It is necessary to identify and evaluate it in the companies. There are many insurance companies on the market that offer insurance against business risks. Horita et al. (2018) claimed that risk is the pillar of multi-criteria decision-making.

They have applied and evaluated the disaster risk by monitoring and early-warning in Brazil. For people assessment, the Assessment centre and Development centre were developed. These methods, such as Krulis (2011) have noted, are considered to be the most comprehensive and thorough assessment method for people. They bring complex view on abilities, skills and reserves of evaluated persons (Krulis, 2011).

\subsection{Summary and evaluation}

According to the results of total or relative utility and after the risk evaluation is necessary to assess the options. It can be used the simple table which summarize achieved results.

\subsection{Decision making and justification}

Justification represents the manager's rationale for the decision. It must be accepted by all stakeholders.

\section{Application of decision making in web developer position}

\subsection{Managerial problem description and characteristics and goal setting}

The problem will be described as the case study in human resources department of the company, which wants to be and stay competitive on the market. It wants to increase the amount of sales. For sales increasing, it is necessary to have customeroriented web sites. That is why the company is looking for hiring the highly reliable and experienced employee at the IT department who will be responsible for the content and functionality of the web sites. The task for the HR department is to find a responsible web designer. The company has advertised a tender for the position of web designer in the IT department.

\subsection{Analysis of decision-making factors, determination of criteria and rules}

Web applications providing is a very important tool that is necessary for successful trading. Web designer should know how to organize the data on the web page, how to control the flow of the web application by analyzing the structure and relationships of the widgets in the mockup, etc. There are many reasons why to choose the web designer carefully - many subjects can attack the running application, affect the functionality of the web site, disable access to harm the provider and the entire company.

\subsection{Determination of criteria}

The following criteria were determined from the curriculum vitaes: experience in the branch (C1), achieved education level (C2), hard skills (C3), such as knowledge of web design platform e.g. HTML language, Java language, JavaScript, PHP, other hard skills (C4) such as graphical tools knowledge, such as the Corel or Gimp, etc., knowledge of coding and testing of the web functionality (C5), such as the Sbi or Silenium, social skills (C6) such as the working under stress and foreign language proficiency (C7), especially English.

\subsection{Determination and development of options}

The following facts were identified from the CVs and motivation letters:

\subsubsection{Option No. 1: Applicant No. 1}

Experience in the industry: 4 years, achieved education level: Bachelor, knowledge of HTML, Java language and JavaScript, PHP knowledge, knowledge of graphical tools: Adobe Photoshop, coding and testing, social skills: working under stress, reliability: satisfactory, foreign language proficiency: English at communication level.

\subsubsection{Option No. 2: Applicant No. 2}

Experience in the industry: 2 years, achieved education level: technical university, experience with web pages creating, knowledge of platforms: HTML, Java, JavaScript, PHP knowledge, Pinnancle studio, Corel, language R, Adobe Photoshop, coding, social skills: responsibility, working under stress, problem solving, excellent, foreign language proficiency: English - speaking and writing.

\subsubsection{Option No. 3: Applicant No. 3}

Experience in the industry: none, achieved education level: high school, knowledge of HTML, Java platforms, PHP, ASP.Net; social skills: reliability - good, testing, foreign language proficiency: English - speaking and writing, 1 year internship in the USA. The information above was summarized in the following criteria:

- Praxis - criteria C1

- Education level - C2

- Hard skills - C3

- Other hard skills - C4

- Coding and testing - C5

- Social skills - C6

- Foreign languages - C7

Above mentioned criteria have been evaluated and processed by using the matrixes of absolute utilities, simple utilities, Saaty's matrix and matrix of weighted utilities which are detailed in Tables 4-7. 
Table 4: Matrix of absolute utilities

\begin{tabular}{cccc}
\hline Criteria & Applicant No. 1 & Applicant No. 2 & Applicant No. 3 \\
\hline $\mathrm{C}_{1}$ & 4 years & 2 years & none \\
$\mathrm{C}_{2}$ & Bachelor & Master's digree & High school \\
$\mathrm{C}_{3}$ & HTML, Java, JavaScript, PHP & Java, JavaScript, PHP, HTML & HTML, Java, JavaScript, PHP, ASP. net \\
$\mathrm{C}_{4}$ & Adobe Photoshop, Plug in, Site Manager & Pinnancle Studio, Corel, language R & Corel, language R, \\
$\mathrm{C}_{5}$ & coding and testing & coding & testing \\
$\mathrm{C}_{6}$ & satisfactory & excellent & good \\
$\mathrm{C}_{7}$ & at communication level & speaking and writing & at communication level \\
\hline
\end{tabular}

Table 5: Weights of criteria - application of the Saaty's matrix

\begin{tabular}{lc}
\hline & \multicolumn{2}{c}{ Weight } \\
\cline { 2 - 2 } C1 & 0.355 \\
C2 & 0.025 \\
C3 & 0.213 \\
C4 & 0.077 \\
C5 & 0.055 \\
C6 & 0.124 \\
C7 & 0.150 \\
\hline
\end{tabular}

Table 6: Matrix of simple utilities

\begin{tabular}{cccc}
\hline Criteria & Option 1 & Option 2 & Option 3 \\
\hline $\mathrm{C}_{1}$ & 100 & 80 & 0 \\
$\mathrm{C}_{2}$ & 80 & 100 & 0 \\
$\mathrm{C}_{3}$ & 100 & 100 & 50 \\
$\mathrm{C}_{4}$ & 80 & 100 & 60 \\
$\mathrm{C}_{5}$ & 100 & 50 & 50 \\
$\mathrm{C}_{6}$ & 80 & 100 & 90 \\
$\mathrm{C}_{7}$ & 70 & 90 & 100 \\
\hline
\end{tabular}

Table 7: Matrix of weighted utilities

\begin{tabular}{cccccc}
\hline Criteria & Weight & Option 1 & Option 2 & Option 3 & $\begin{array}{c}\text { Option } \\
\max \end{array}$ \\
\hline $\mathrm{C}_{1}$ & 0.355 & 35.476 & 28.381 & 0.000 & 35.476 \\
$\mathrm{C}_{2}$ & 0.025 & 1.986 & 2.483 & 0.000 & 2.483 \\
$\mathrm{C}_{3}$ & 0.213 & 21.348 & 21.348 & 10.674 & 21.348 \\
$\mathrm{C}_{4}$ & 0.077 & 6.191 & 7.739 & 4.644 & 7.739 \\
$\mathrm{C}_{5}$ & 0.055 & 5.515 & 2.758 & 2.758 & 5.515 \\
$\mathrm{C}_{6}$ & 0.124 & 9.914 & 12.393 & 11.154 & 12.393 \\
$\mathrm{C}_{7}$ & 0.150 & 10.533 & 13.542 & 15.047 & 15.047 \\
$\mathrm{TU}$ & 1.000 & 90.963 & 88.643 & 44.275 & 100.000 \\
$\mathrm{RU}$ & & 90.963 & 88.643 & 44.275 & \\
\hline
\end{tabular}

\subsection{Risk evaluation}

This study consists of identification of the 5 risks which forecast option selection consequences. The risks are listed below:
R1 - Low performance of the employee

R2 - Conflicts with managers

R3 - Inability to work under pressure

R4 - Inability to work due to high sickness absence level

R5 - Will not fit in the collective due to absence at company events

The pairwise comparison of risks was determined by Saaty's matrix and is shown in Table 8 . The most importance of the risk factor has the low performance of the employee.

Table 8: Weights of different risk factors

\begin{tabular}{cc}
\hline Type of risk & Weight \\
\hline R1 & 0.293 \\
R2 & 0.235 \\
R3 & 0.235 \\
R4 & 0.189 \\
R5 & 0.047 \\
\hline
\end{tabular}

To express the total and percentage share of risk posed by the different options, the risk degree must be calculated - shown in Table 9.

Results by application the decision analysis showed, that advantage of the first applicant is his experience in the industry, knowledge of HTML, Java language and JavaScript, knowledge of graphical tools and coding and testing. For that reason it would not be difficult to provide induction training to him. The company can offer him the English course. This applicant had the best result according to the utility assessment and second best result according to the risk assessment, as indicated in Table 10.

Table 9: Matrix of risk factors

\begin{tabular}{|c|c|c|c|c|c|c|c|c|}
\hline Criteria & $\mathrm{W}^{*}$ & $\mathrm{Lik}^{* *}$ & L1 & Lik $^{* *}$ & $\mathrm{~L} 2$ & Lik $^{* *}$ & L3 & $\mathrm{Lik}^{* *}$ \\
\hline R1 & 0.293 & 0.3 & 0.0879 & 0.1 & 0.0293 & 0.5 & 0.1465 & 0.1465 \\
\hline $\mathrm{R} 2$ & 0.235 & 0.3 & 0.0705 & 0.3 & 0.0705 & 0.3 & 0.0705 & 0.0705 \\
\hline R3 & 0.235 & 0.2 & 0.047 & 0.4 & 0.094 & 0.5 & 0.1175 & 0.1175 \\
\hline $\mathrm{R} 4$ & 0.189 & 0.2 & 0.0378 & 0.2 & 0.0378 & 0.2 & 0.0378 & 0.0378 \\
\hline R5 & 0.047 & 0.2 & 0.0094 & 0.1 & 0.0047 & 0.1 & 0.0047 & 0.0094 \\
\hline Total & & & 0.2526 & & 0.2363 & & 0.377 & 0.3817 \\
\hline Risk & & & 66.18 & & 61.91 & & 98.77 & \\
\hline
\end{tabular}

\section{Results and discussion}

Applicant No. 2 has advantage in amount of hard skills and graphical tools, good English speaking and writing skills and his education (but we can see low importance of these criteria). The language skill is actually of importance for the company because it has entered into contracts with foreign partners and intends to implement foreign projects.
Applicant No. 3 is a person with secondary education and without any experience. The company would have to provide several months' induction training to him. However, his advantage is his young age so he can be expected to quickly fit in the collective and, in addition, to present opinions and attitudes not conflicting with the director. His advantage is the experience in the USA, that's why it is expected excellent English and understanding the software manuals will be easier. 
Applicant no. 1 was selected as the most appropriate applicant for the position specified above based on objective assessment, i.e. application of decision-making process. Applicant No.1 meets the defined criteria best and poses the second lowest risk. The problem has been solved. The multi-criteria decision process has been implemented for selection of the most appropriate applicant for the position of web designer. There are many models of HR managers, which are described by Armstrong (2006). The advantage of this survey is that an innovative HR manager can quickly acquire rating of the seeker and immediately compare his knowledge and skills from the curriculum vitae. The second advantage is that the HR manager can evaluate the risk factors of the candidate also. Armstrong (2006) prefers the assessment centre for the evaluation of the applicants on different work positions. He prefers evaluation of the applicant according to a questionnaire, interview and references. This way of evaluation seems to be open-minded, but expensive, and sometimes lengthy and ineffective, as the interviewees may not tell the true.

Table 10: Evaluation of order according to utility and risk

\begin{tabular}{cccc}
\hline Order & 1. & 2. & 3. \\
According to utility (U) & 1. & 2. & 3. \\
According to risk (R) & 2. & 1. & 3. \\
\hline
\end{tabular}

\section{Conclusion}

The above mentioned example is a proof of that the decision-making can be used during determination of criteria and selection of option between separate candidates for a job position and can become an integral part of the selection procedure. The manager assessed the applicants not only from the utility view but risk view too. The usage of multi-criteria decision-making process in human resources management is unambiguous.

\section{Acknowledgement}

This paper was supported within Operational Programme Education for Competitiveness - Project No. CZ. 1.07/2.3.00/20.0296 and SP2017/141.

\section{Compliance with ethical standards}

\section{Conflict of interest}

The authors declare that they have no conflict of interest.

\section{References}

Anderson DR, Sweeney DJ, and Williams TA (1988). Instructor's manual with solutions to accompany an introduction to management science: Quantitative approaches to decision making. West Publishing Company, Eagan, Minnesota, USA.

Armstrong M (2006). A handbook of human resource management practice. Kogan Page Limited, London, UK.

Castro-Nuño M and Arévalo-Quijada MT (2018). Assessing urban road safety through multidimensional indexes: Application of multicriteria decision making analysis to rank the Spanish provinces. Transport Policy, 68: 118-129. https://doi.org/10.1016/j.tranpol.2018.04.017

Horita FE, de Albuquerque JP, and Marchezini V (2018). Understanding the decision-making process in disaster risk monitoring and early-warning: A case study within a control room in Brazil. International Journal of Disaster Risk Reduction, 28: 22-31.

https://doi.org/10.1016/j.ijdrr.2018.01.034

Charlesworth D (2017). Decision analysis for managers: A guide for making better personal and business decisions. Business Expert Press, New York, USA.

Khan MI (2018). Evaluating the strategies of compressed natural gas industry using an integrated SWOT and MCDM approach. Journal of Cleaner Production, 172: 1035-1052. https://doi.org/10.1016/j.jclepro.2017.10.231

Krulis J (2011). How to win over the risks. Active risk management - A tool for managing successful businesses. Linde, Prague, Czech Republic.

Ministr J (2013). The influence of human resources on the IT service management. In the $35^{\text {th }}$ International Conference on Information Technology Interfaces (ITI), IEEE, Cavtat, Croatia: 323-328.

Pineda PJG, Liou JJ, Hsu CC, and Chuang YC (2018). An integrated MCDM model for improving airline operational and financial performance. Journal of Air Transport Management, 68: 103117.

https://doi.org/10.1016/j.jairtraman.2017.06.003

Purcarea A, Popescu M, and Gheorghe S (2017). Online platformsmethod of promoting an IT company through social media. In the $25^{\text {th }}$ Interdisciplinary Information Management Talks Confrence in Digitalization in Management, Society and Economy, Trauner Verlag Universität, Poděbrady, Czech Republic: 201-208. PMid:29362593 PMCid:PMC5771248

Řeháček P (2015). Organization forms for project management. In the $25^{\text {th }}$ International Business Information Management Association Conference, IBIMA, Amsterdam, Netherlands: 2092-2101.

Řeháček P (2018). Risk management standards for P5M. Journal of Engineering Science and Technology, 13(1): 11-34.

Saaty T and Vargas L (2001). Models, methods, concepts and applications of the analytic hierarchy process. Kluwer Academic Publishers, Boston, Massachusetts, USA. https://doi.org/10.1007/978-1-4615-1665-1

Zaman UK, Rivette M, Siadat A, and Mousavi SM (2018). Integrated product-process design: Material and manufacturing process selection for additive manufacturing using multi-criteria decision making. Robotics and Computer-Integrated Manufacturing, 51: 169-180.

https://doi.org/10.1016/j.rcim.2017.12.005 